\title{
JANSENISMO Y REGALISMO \\ EN EL SEMINARIO DE SAN FULGENCIO DE MURCIA(*)
}

\author{
Por Cayetano MAS GALVAÑ
}

Universidad de Alicante

Als meus pares

En el estudio de la cultura española del siglo XVIII, el colegioseminario conciliar de San Fulgencio de la ciudad de Murcia adquiere personalidad propia como importante foco de difusión del pensamiento janseista y de las ideas ilustradas. La fama que en ese sentido adquirio entre sus contemporáneos perduró a lo largo del siglo XIX; sambenito éste que ha llegado hasta nuestros días(1).

Sin embargo, carecíamos de los necesarios estudios sobre la evolución cultural del colegio durante su etapa más significativa (el último cuarto del siglo XVIII y la primera década del XIX) que ayudasen a centrar el problema desde unas perspectivas distintas a las proporcionadas por el simple tópico(2). Bien es cierto; por otra parte, que este trabajo sólo ha sido posible, desde un enfoque adecuado, cuando la evolución reciente de la historiografia sobre la cultura española del siglo XVIII (y en concreto, sobre nuestro jansenismo), ha permitido articular los estudios más especificos y de menor envergadura sobre líneas cientificas realmente operativas.

(") Este trabajo desarrolla parte de la tesis de licenciatura que, con el mismo titulo, lei en la facultad de Filosofia y Letras de Alicante, bajo la dirección de D. Antonio Mestre Sanchis, el 13 de noviembre de 1981. 
Centrando el tema, pues, en la problemática del jansenismo, se hace necesario, en principio, analizar el sentido y la naturaleza que tal movimiento adoptó en nuestro país.

Desde la perspectiva europea, el nuestro es el más tardío de los jansenismos nacionales. A primera vista, resalta la complejidad de su contenido. Se trata de la "quasi-imposibilidad de dar al término jansenismo un contenido intelectual preciso (...), de definir el jansenismo como un sistema cerrado de ideas que se podrían analizar de una vez por todas «(3). Es decir, que este movimiento entraña, además de unos principios doctrinales sobre la gracia y la predestinación, una serie de actitudes morales rigoristas, y político-temporales, que irán evolucionando hasta ocupar el primer plano de su forma de ser posterior(4).

La aparición de estos últimos componentes-presentes igualmente en España-generó la adopción de una serie de posturas enfrentadas entre sí. Las controversias que siguieron, sobre la naturaleza del jansenismo español, pasaron de los propios "contemporáneos a nuestros historiadores del pasado siglo (Menéndez Pelayo y el P. Miguélez), para manifestarse ante los estudiosos actuales de la llustración en los paises católicos, como problema histórico de primer orden.

Estudiando las conexiones del jansenismo europeo con la llustración, L. Ceyssens ha hecho una de las mejores aportaciones, al distinguir el jansenismo tomado en el sentido teológico (restringido a las cinco proposiciones condenadas en la bula papal "Cum occasione", de 1.653), del jansenismo entendido en un sentido "histórico». Este último, sin aceptar ninguna de las proposiciones condenadas, sí responde a una forma de religiosidad de características definidas. Para precisar en cada momento el significado del término, es preciso partir del hecho de que la existencia de la oposición jansenistas-antijansenistas da origen a dos partidos antitéticos que evolucionan delimitando mutuamente sus conceptos: el jansenismo crea el antijansenismo, siendo el jansenismo histórico; en cada momento concreto, aquello que quieren indicar los antijansenistas.

Appolis, por su parte, ha evidenciado la existencia, entre ambos partidos extremos, de un grupo de moderados ( $(T i e r s$ parti»), que pretendio establecer un equilibrio en el campo doctrinal y moral. Gran parte de los jansenistas españoles puede ser incluida en este, grupo, con lo cual se establece la conexión del jansenismo español dentro de las coordenadas del pensamiento religioso europeo.

Desde sus respectivos prismas nacionales, otros historiadores europeos se han ocupado de estas relaciones. Así, J. Saugnieux ha precisado las corrientes europeas, especialmente francesas, que se dan en el janse- 
nismo español. De importancia capital es, igualmente, la contribución de los estudiosos italianos. Sin descuidar los trabajos de Jemolo y Codignola, habria que insistir especialmente en los realizados por Dammig sobre el jansenismo romano, por cuanto nos permiten explicar la actividad de los españoles (políticos, como Roda o Azara; religiosos, como Francisco X. Vázquez), y el influjo que ejercieron sobre quienes visitaban Roma o ampliaban alli sus estudios(5).

Finalmente, los trabajos de A. Mestre a proposito de la figura de D. Gregorio Mayans arrojan luz sobre las raíces y la cronología del movimiento en España. Paralelamente al desmonte de la interpretación clásica sobre los orígenes del pensamiento ilustrado en España, demostrando la trascendencia y lo temprano del foco intelectual valenciano, los trabajos de Mestre resaltan el carácter fundamentalmente religioso del jansenismo y su inserción dentro de las coordenadas de la religiosidad europea del siglo. Mayans, en contacto permanente con Europa, conoce el pensamiento $y$ los autores jansenistas europeos ya en la década de 1720-1730, al tiempo que las corrientes ilustradas. La influencia del grupo valenciano se proyectará, con personalidad propia, determinando los acontecimientos culturales de toda nuestra llustración. $Y$ es precisamente en este grupo donde tomará carácter un elemento presente en la base de la postura religiosa de nuestros ilustrados: la herencia de la tradición hispánica, del pensamiento español del siglo XVI en general y de los erasmitas en particular, generadora del interés por el conocimiento de la Biblia y por el regalismo(6).

\section{II}

Respecto al objeto de este artículo (el estudio de la evolución seguida por el seminario de San Fulgencio a partir de 1774, año del comienzo de su reforma), es necesario explicar las causas que provocaron su conversión en:

1. Centro de carácter universitario, a efectos prácticos, transgrediendo (aparentemente y por exceso) su estatuto como seminario conciliar. Este va a ser un caso único en su género.

2. Foco avanzado en la difusión del pensamiento jansenista y de las ideas ilustradas, anticipándose (en todos los terrenos) sobre la mayoría de las auténticas universidades. El fenómeno resulta más sorprendente aún' si se tiene en cuenta que el seminario carecia de antecedentes culturales en esa línea.

Una serie de causas complejas y de circunstancias de diverso tipo nos ofrecen las claves para el entendimiento del problema. Lógicamente, 
un primer grupo de factores son los derivados de aquéllos otros que, en el terreno cultural y político, determinaron la evolución general del pais. Exponiéndolos esquemáticamente, serian:

La vinculación entre católicos ilustrados y jansenistas, que aparece como indisoluble en muchas de las personalidades concretas. No obstante, a nivel de corrientes diferenciadas (en proceso de convergencia a lo largo del siglo), algunas cuestiones establecen claramente los nexos: "el odio a la escolástica y a las tradiciones eclesiásticas más recientes, el deseo de una religiosidad interior, una mayor valoración del episcopado y de los concilios nacionales, cierta antipatía por las ordenes religiosas a causa de sus privilegios y exenciones, constituian los puntos fundamentales que, pese a otras divergencias, unían a los ilustrados y jansenistas frente a un ambiente religioso que consideraban decadente $y$ superficials(7).

La conversión del jansenismo en ideología del poder, a partir del "viraje jansenista" que tiene lugar con la caída del triángulo CarvajalEnsenada-Rávago. Las implicaciones político-sociales del hecho son trascendentales. Supone, dentro del regalismo, el fin del apoyo en una escuela doctrinal y en una clase social (los probabilistas, es decir la Compañia de Jesús; y la aristocracia, a través de los Colegios Mayores), y su sustitución por otras distintas (los probabilioristas, dominicos y agustinos; los manteistas), que pasarán a ser las dominantes durante todo el reinado de Carlos III.

Resultan obvias, pues, las vinculaciones entre regalismo y jansenismo (este último como aparato ideológico esgrimido en favor del primero a manos de los manteístas y frente a sus enemigos), aunque en España el fenómeno se produjo mucho más tardiamente que en Francia. Pese a ello, ambas corrientes no son idénticas ni por sus principios doctrinales ni por su origen histórico, y habian seguido líneas claramente separadas durante la primera mitad del siglo. El círculo se completa cuando establecemos la relación existente entre este jansenismo cargado de matices regalistas y las posturas de los ilustrados, hecho éste también general en Europa.Los ilustrados, que apoyaban el regalismo, tomaron partido por la tendencia rigorista y en favor de la religiosidad interior, del mismo modo que el ejercicio de la crítica los induce al estudio histórico de las fuentes del cristianismo y de la Iglesia Primitiva, censurando la actividad exterior de la Iglesia personalizada en la Curia. En última consecuencia, serán rigoristas en moral y atacarán al laxismo y a los casuistas. Por otra parte, su idea de que la única fuerza capaz de realizar sus proyectos es el rey (eje de la reforma social que pretenden) les hace colaborar-pese a sus profundas diferencias -, con el despotismo ilustrado(8).

En el campo de la Iglesia, con la elevación de la calidad del episcopado respecto de la anterior centuria, durante la primera mitad del siglo XVIII 
se perfila claramente el ideal del cumplimiento de los mandatos Tridentinos, a nivel general entre los obispos. Dentro de estas esferas, a mediados de siglo comienzan a observarse cambios que llevarán a amplios sectores, primero, hacia posiciones antijesuitas, y posteriormente jansenizantes. La influencia del foco valenciano (surgido del círculo Mayans-Mayoral), generará a su vez nuevos focos de difusión jansenista en Salamanca y Barcelona (respectivamente, los obispos Bertrán y Climent).

Presente el jansenismo, pues, tanto en las élites ilustradas del país, como en amplios sectores del episcopado, y convertido en arma ideológica de los manteístas en el poder, la reforma de la sociedad propugnada por los ilustrados y asumida por el Estado se presentó con claros contenidos jansenistas. Dentro de la mentalidad de la época, el medio fundamental para la trasnformación era la reforma de la enseñanza, tanto en el terreno seglar como en el eclesiático. Junto a la nueva pedagogía, el regalismo aparecia como factor decisivo. En conclusión, reforma general, reforma universitaria y reforma eclesiástica se presentaban como aspectos íntimamente relacionados.

En el caso concreto de San Fulgencio, otro tipo de circunstancias que determinaron su evolución durante el período que estudiamos son las que dimanan de su propia entidad en cuanto centro docente en general y como seminario en particular, con una larga historia que arrancaba desde finales del siglo XVI. No pueden tampoco ser olvidados los factores de orden local, es decir, los condicionamientos que sufrió como institución inserta en el ambiente social concreto de Murcia. En la medida en que la intervención estatal sólo se dará (bien que con carácter casi exclusivo) desde 1768 (Real Cédula de 14 de agosto sobre "Erección de seminarios conciliares»), este último grupo de influencias serán las que regirán la vida del seminario hasta las reformas de la década de 1770-1780.

Desde su fundación en 1592 hasta las reformas de 1774, el seminario de San Fulgencio siguió una trayectoria semejante a la del resto de las instituciones conciliares españolas. Sin perder nunca (tampoco después de la última fecha) su inicial estatuto Tridentino (las reformas carlotercistas son las responsables de que por vez primera los seminarios alcanzasen la plenitud en el cumplimiento del decreto upro seminariis", de 1563), hubo de adaptarse a la situación general de la sociedad española en cada momento, y a la del sistema educativo en particular.

Los seminarios españoles atravesaron lánguidamente el Barroco. Abandonados por Roma y por el Estado, carentes de recursos económicos y jugando un papel secundario en el sistema educativo (predominio de los colegios de la Compañía de Jesús en la enseñanza que pudiéramos llamar secundaria), la mayoria_también el murciano-pasaron a ser controlados por los cabildos catedralicios, en presencia de obispos indolentes o desinteresados(9). 
Los primeros indicios de cambio se darán en la primera mitad del siglo XVIII. La labor Ilevada a cabo por los prelados murcianos que ocupan ese período-en especial, Belluga-preparo el terreno para las posteriores reformas. Ausente aún la intervención estatal, estos obispos asumirán el papel protagonista, dispuestos a hacer valer su autoridad ante los cabildos, para el exacto cumplimiento de los decretos tridentinos. Belluga, sin rupturas ni enfrentamientos, sienta las bases para la emancipación de las servidumbres que gravaban al seminario en el servicio de la catedral, lo dota de nuevas constituciones y mayores medios economicos, y establece los estudios de filosofía y teología para los seminaristas (hasta entonces inexistentes, limitados como estaban a la gramática latina y la moral), mediante el sistema de asistencia, divididos por escuelas, a las aulas públicas de los conventos de la ciudad(10). Preocupado por la formación sacerdotal, creó un seminario para el perfeccionamiento de los teólogos (el de San Isidoro), confiándolo a la dirección de los upios operarios evangélicos", del P. Ferrer, uno de los movimientos de reforma sacerdotal en vanguardia(11). Finalmente, en 1741 erigía las dos primeras cátedras superiores en el interior del seminario, una para el derecho civil, y la otra para el canónico(12).

La anómala aparición de la cátedra de derecho civil en el interior de un seminario clerical(13), encuentra su razón en el carácter mixto (eclesiástico-seglar), que tuvieron los seminarios en su historia anterior: su inserción en el sistema educativo español los hizo actuar en respuesta a la demanda social de enseñanza, abriendo sus aulas a los alumnos seglares. Así ocurrió en Murcia con la cátedra de gramática latina durante todo el siglo XVII, y a mediados del siglo XVIII con las de derecho: la mejoría económica y social del nuevo siglo, y la inexistencia de universidad (en una época en que faltaba el aparato docente estatal), hizo canalizar la satisfaccion de la necesidad de estudios universitarios hacia la Iglesia y sus instituciones, en concreto hacia la persona de su gran cardenal protector, Belluga, y su seminario de San Fulgencio. Es el primer precedente de la evolución universitaria del seminario.

Los sucesores de Belluga (en especial D. Diego de Roxas Contreras, obispo de Murcia de 1752 a 1772) continuaron el camino emprendido. Como consecuencia, al comenzar el pontificado de D. Manue! Rubin de Celis, esta sana corriente de reforzamiento de la autoridad episcopal había conseguido que el seminario alcanzase una posición sustancialmente distinta de la que ofrecía al comenzar el siglo: con rentas suficientes y alumnado numeroso, emancipado-como disponía el Concilio-de cualquier instancia ajena a la episcopal, con un programa de estudios completo para sus alumnos, e incluso con cátedras de derecho en su mismo interior.

Este proceso hacia la adquisición de rango universitario no hubiera sido posible sin la presencia de un fenómeno de carácter general, patente a 
finales del siglo XVII: la decadencia de las universidades. Vinculadas a los intereses del grupo que ellas mismas formaron-los profesionales del derecho-, habíanse alejado del conjunto de la sociedad para centrarse en los Colegios Mayores, el estudio de la jurisprudencia y la consecución de los cargos de letrados, desde una perspectiva ideológica francamente inmovilista(14). Con ello, quedaban abiertos nuevos caminos para el resto de las instituciones docentes, en las que necesariamente habia de encauzarse todo el proceso de innovación científica o cultural. Estas son, pues, las coordenadas (generales y locales), de las que el seminario murciano se beneficio, facilitando el avance de la reforma mucho más que instituciones de mayores proporciones y de más larga tradición, cuales eran las universidades.

Ya en el poder, el grupo manteísta había de asegurarse el control en la difusión ideológica. De ahí que la reforma de la enseñanza pasase por el extrañamiento de sus principales oponentes (los jesuitas), la reforma de las viejas estructuras (Colegios Mayores y universidades) y la propagación del jansenismo.

En materia de seminarios, la citada Real Cédula sobre seminarios conciliares (1768), cargada de matices regalistas e ilustrados, marca el punto de partida para la intervención estatal(15). En ella, el rey se arrogaba el derecho de intervenir forzando el cumplimiento del decreto tridentino "pro seminariis", dando comienzo a una etapa de esplendor en cuanto a reformas y fundaciones de seminarios. Por otra parte, la política seguida en este terreno por el gobierno presenta fuertes parecidos y vinculaciones con la desarrollada en las universidades. A los iniciales impetus centralizadores (la real cédula disponía que se redactase un plan de estudios común para todos aquéllos), sucedió la inclinación gubernamental por las soluciones parciales(16). De este modo se introducia un elemento diferenciador en la política estatal, que vino finalmente a posibilitar la evolución hacia la universidad de que venimos hablando para el colegio fulgentino.

En definitiva, desde 1768 la influencia de la corriente regalista sobre los seminarios será dominante y excluyente. Hacia esas alturas del siglo, los dos grandes agentes de la reforma que entonces comenzaba habian alcanzado el punto común de su anterior convergencia. De un lado el rey y su instrumento, el regalismo. De otro, los obispos, con un importante sector filojansenista o, cuando menos, favorable a las regalías. Uno y otros, rey y obispos, eran conscientes, cada cual en su posición, de la necesidad de apoyo mutuo que se debían, en un momento en que los objetivos se mostraban comunes. 
Fue D. Manuel Rubin de Celis, obispo de Cartagena entre 1773 y 1784 , el autor de la reforma del seminario. Tan citado como poco estudiado(17), su personalidad nos coloca ante un prelado que auna en su carácter las vinculaciones existentes entre jansenistas e ilustrados. Su biografía ofrece, en este sentido, algunas notas reveladoras. De origen noble y acaudalado, se formo como jurista y mantuvo, como evidencia de su trayectoria ascendente, buenas relaciones con los gabinetes ilustrados de Carlos III. Pero importa, sobremanera, su estancia en el colegio "De propaganda fiden romano, en donde, aparte de conocer personalmente al P. Jacquier, se familiarizaria con la problemática religiosa italiana de mediados de siglo(18). Sin temor al error, podemos afirmar que (como señalaba Dammig para el caso de otros españoles), también el influjo recibido por Rubín durante su estancia en Roma, determinó su inclinación filojansenista y su postura abierta ante las ideas ilustradas.

Los dos planes de estudios otorgados por D. Manuel al seminario de San Fulgencio en 1774 (filosofía y teología) y 1778 (derecho civil y canónico)(19) constituyen la mejor base para el análisis de su pensamiento, a la vez que la base de la reforma de que estamos tratando. Continuando la labor de sus predecesores en la sede murciana, y apoyándose en la Real Cédula sobre seminarios, los planes comportaban innovaciones estructurales que venían a culminar el proceso abierto por Belluga. Con la creación de cátedras de filosofía y teología en el interior del colegio, Rubín ponía fin a las salidas diarias que el seminarista tenía que hacer fuera de la casa, a la vez que a la división del alumnado por escuelas y al monopolio que sobre la enseñanza de los fulgentinos gozaban los regulares.

Pero la auténtica innovación se registra en el contenido básico de los planes, el cultural y el pedagógico. $Y$ en este terreno, los nuevos textos desempeñan el papel central.

La filosofía se cursaba en tres años, comprendiendo las materias de lógica y primera parte de la metafísica; segunda parte de la metafísica y física general; y física particular y filosofía moral o ética, respectivamente en cada curso. El texto elegido son las «Institutiones philosophicae ad studia theologica potissimum accomodatan, del P. F. Jacquier(20), colocado por Herr en la misma línea de Ilustración-oficialmente aceptada-que sostenían autores como Bacon, Descartes, Newton, Leibniz, Wolf, Locke, Condillac, etc. La obra comenzaba con dos tomos de lógica y ontología de sabor escolástico, pero los restantes trataban libremente de aritmética, álgebra, geometría, física, astronomía, geografía y filosofía moral(21).

Es en los estudios de teología donde claramente aparece el jansenismo del prelado. D. Manuel creó un cátedra de lugares teológicos, tres de teología escolástica (aunque los años de enseñanza se convirtieron, más 
tarde, en cuatro), y una de teologia moral (con dos años de enseñanza).

Para la primera, el texto era el tratado "De Locis Theologicis" de Gaspar Juenin(22), autor conocido por sus tendencias filojansenistas y por su rigorismo moral. Postura que se confirma en el texto prescrito para la enseñanza de la teología moral, el compendio "Theologia christiana dogmatico-moralis", del P. Daniel Concina, conocido por su antiprobabilismo acérrimo, oposición a los casuístas y por las polémicas que sostuvo con los jesuítas en Italia(23).

Junto al rigorismo, el agustinismo doctrinal: en las cátedras de teología doctrinal se estudiaba la obra del P. Lorenzo Berti "De theologicis disciplinis", a través del compendio elaborado por el P. Gerónimo M. Buzi(24).

En relación con el plan, cabe la formulación de algunas consideraciones generales. A primera vista se observa, en los textos, una innovación propia del siglo XVIII y de los planteamientos ilustrados: la preferencia por la elección de compendios, con el fin de proporcionár al estudiante una visión clara y concisa de los conocimientos que se consideran necesarios para su formación. Ahora bien, esta aparición del compendio se encuentra ligada con el esfuerzo ilustrado por desterrar el engorroso método escolástico. Rubín dio el primer paso aboliendo el sistema de las escuelas, completado ahora con la selección de textos completamente nuevos.

Es preciso notar que los planteaminetos de Rubin distan del radicalismo presente en algunos ilustrados (como Olavide o el P. Truxillo), para acercarse a los más moderados formulados por Mayans en su plan general para la enseñanza universitaria, de 1767(25). El valenciano, a la par que deseaba la separación entre dogma y escolástica-demandando un compedio de teología dogmática-, consideraba que la escolástica no debía ser desterrada totalmente, pues formaba parte de la evolución del pensamiento cristiano. $Y$ a pesar de la denominación utilizada por Rubín (teología "escolástica"), en realidad seguia la línea de D. Gregorio al decidirse por adoptar un compendio en donde se resumia y separaba el dogma de la escolástica. Este criterio es el que aplicó también al establecer una cátedra de lugares teológicos separada de las restantes(26).

La cuestión es nítida en lo que atañe al método de enseñanza que elige, básicamente integrado por las clases y los actos académicos (academias, conclusiones y lecciones de puntos). Las primeras se basaban en la explicación del profesor y en las preguntas que éste formulaba a sus alumnos. El método escolástico de las argumentaciones quedaba reducido a un corto espacio en los momentos finales de la clase, y sólo con vistas a que el alumno dominase su funcionamiento de cara a los actos académicos o a su posterior vida profesional. Dichos actos conservaron más ampliamente el método escolástico, pero se orientaban hacia ese mismo 
objetivo. Erradicadas las engorrosas disputas, la escolástica era devuelta a su primitivo fin: servir como herramienta de trabajo intelectual, pero nunca como fuente de conocimiento.

La exacta ponderación de la importancia del plan de 1774 exige situarlo en relación con la situación general de la enseñanza universitaria. Destaca aquí el aspecto cronológico. Mientras que la introducción de textos como el de Jacquier sólo puede considerarse masiva en la década de 1780 , el seminario murciano es sin duda uno de los primeros centros que lo adopto(27). Y si la práctica totalidad de los seminarios españoles entraron en franca dependencia, en materia de planes de estudios y textos, respecto de las universidades (habida cuenta de la política de incorporaciones seguida por el Consejo), con el plan de teología del seminario de San Fulgencio asistimos a la inversión de tales términos.

En efecto, Valencia fue el otro gran centro en donde el agustinismo cobró fuerza(28), especialmente durante el tiempo en que Juan Antonio Mayans fue rector de la universidad (1775-1778). No extraña pues el interés que allí se levantó por el plan de estudios murciano: casi inmediatamente (31 de marzo de 1775), el rector y claustro de la universidad valentina pidieron licencia al Consejo para establecer alli los mismos textos que en el seminario fulgentino. Esta situación de vanguardia cronologica no se hubiese dado a no ser por la concurrencia de una serie de condiciones:

1. La autonomía jurídica del seminario, por su estatuto conciliar, que le colocaba en dependencia directa y exclusiva respecto del obispo.

2. La aparición en la sede murciana de un obispo reformista.

3. El apoyo del Estado regalista.

Sin las trabas que ofrecian las universidades para la introducción de los nuevos planes, propugnada por el Consejo, en Murcia bastó la eficaz alianza entre un obispo reformista y un gobierno que sostenia los mismos criterios para que el seminario se elevase hasta cotas insospechadas que, como indicábamos, eran impropias a su fin y al que en principio había marcado el propio Estado.

No obstante, en los primeros momentos del cambio, el factor más importante de la innovación fue la mentalidad del obispo. Sin soslayar el hecho de que los autores contenidos en el plan fuesen conocidos en Valencia con bastante anterioridad a 1774(29), es en la estancia italiana de Rubín en donde hemos de centrar nuestra atención (implantación de Berti, Concina y Jacquier), y en general, en la suma de experiencias vitales de D. Manuel (conocimiento de los circulos ilustrados de la Corte).

Algunas ausencias en el plan de 1774 pudieran ser significativas ( $v$. gr., las referencias concretas a las cátedras de Sagrada Escritura), pero 
hallan fácil explicación si consideramos que la misión fundamental del seminario era la formación de sacerdotes, contando con la limitación temporal que imponian las becas de sus alumnos, y la diversidad de materias en las que éstos debían estar versados, que excedian las puramente teológicas. El hecho ya estaba forzando la elección de los compendios. Ahora bien, la misma lectura de estos textos, así como la de alguno de los impresos de conclusiones realizados por profesores y alumnos ${ }^{(30)}$, pone en claro que la enseñanza de teología impartida en el seminario pretendia abarcar esta materia en su totalidad. Mientras que se tocaban materias puramente escriturísticas, dogmáticas o históricas, la Escritura era colocada como fuente principal del conocimiento teológico y la escolástica se veía reducida a un plano secundario. En correlación, se detecta la preocupación por el conocimiento del hebreo y del griego para el estudio del Antiguo Testamento(31).

El jansenismo no podia dejar de aparecer, ahora en sus matices más propiamente jurisdiccionales, en el plan de estudios de derecho (1778). Una primera aproximación obliga de nuevo a efectuar una diferenciación básica. $\mathrm{A}$ las dos cátedras de Belluga, Rubín añadió otras dos (una para derecho civil y otra para el canónico). Con las cátedras de derecho civil, Rubin no hacía más que seguir satisfaciendo una demanda en aumento-son los momentos más prósperos del siglo-, que ya habia sido canalizada hacia el seminario por Belluga(32).

Las posibles incompatibilidades no rigen en cuanto afecta al derecho canónico(33), concebido ahora como prolongación lógica del estudio teológico (no en vano, Rubín se había formado como jurista). Es aquí donde surge prontamente la implicación con el regalismo. En las mentes ilustradas, los obispos y los eclesiásticos en general debian aprender en los cánones a reducir los derechos de la Iglesia a los límites espirituales entendidos según el pensamiento regalista. Este estudio exigía un conocimiento histórico rigurosamente crítico y un método científico(34). Así lo entendia Rubín cuando marco como objeto para los estudios canónicos "la perfecta inteligencia de la Disciplina, y Jurisdicción eclesiástica, y del modo con que en diferentes tiempos se han egercitado una y otraw(35).

Consecuentemente, los cursos se articulan en función del desarrollo histórico, estudiándose primeramente la disciplina antigua y después la nueva (año y medio para cada materia). El texto que utilizarán los estudiantes en la primera asignatura es el de las uInstitutionum canonicarum libri tres", de Julio Lorenzo Selvagio, considerado jansenista por su inclinación galicana(36). Para el estudio de las decretales (derecho nuevo), aunque D. Manuel se inclinó por mantener el texto ya impuesto por Belluga(37), justifica la permanencia del autor (Andrés del Vaulx), en razón del buen juicio que de su obra hiciese Van Espen. Este dato viene a confirmar las tendencias regalistas presentes en Rubin(38). No obstante advertía a los profeso- 
res sobre el manejo de la obra, upues se le notan equivocaciones al autor, ya por falta de crítica, ya también por su modo de resolver en algunos puntos con demasiada indulgencian. Crítica científica y rigorismo moral, derecho canónico y teologia, son aspectos que Rubin de Celis no separa.

El método-en lo tocante al uso de la escolástica-es aún más relajado que en el anterior plan: salvo en los días que estime convenientes, el catedrático ya no dejará tiempo para las argumentaciones en clases y academias.

No obstante estar dirigido al alumnado seglar, la parte del plan de 1778 que se dedica al derecho civil se encuentra en la misma línea que venimos observando. Es aquí, por otra parte, donde mejor apreciamos la coincidencia de criterios entre el obispo y la línea de ilustración oficial: los textos son compendios que el Consejo había aprobado para su implantación en las universidades.

En los dos primeros cursos de esta facultad se estudiaba el derecho romano, utilizando el método comparativo ("Los catedráticos... después de haver explicado a sus Discipulos: lo que el Derecho de los Romanos dispone en los puntos, que comprehende la lección del día, les manifestarán con claridad, y método el Derecho de España en aquellos mismos puntos"). Como texto, las "Justiniani Institutiones Iibri quatuor", con los comentarios de Arnold Vinnen(39).

El tercer año de carrera se dedicaba a la historia de la jurisprudencia (por los compendios de Backio o Brunquelio), y al estudio del derecho natural y de gentes. En la primera disciplina aparece otra novedad pedagógica: junto al manual del alumno, el profesor disponía para su uso particular de los tres tomos del "Originum iuris civilis", escritos por Gian Vicenzo Gravina(40). El influjo de Gravina (que en sus polémicas con los jesuitas tomo postura por los planteamientos filojansenistas) pasó a España-como en otros casos-a través del grupo valenciano, dada su intima amistad con el deán Martí.

Para el derecho natural y de gentes, Rubín impuso los "Elementa juris naturae et gentium", de J. G. Heinecke, reeditados "con correcciones, según la doctrina católica", por D. Joaquín Marín y Mendoza(41). El texto de Marín estaba protegido por el rey para su introducción en las universidades. Destaca Murcia, una vez más, por lo temprano de la fecha en que es adoptado(42).

En el cuarto y último año de enseñanza de jurisprudencia civil se impartía la del derecho común y la legislación de España, por las "Instituciones del Derecho Civil de Castillan, publicadas en 1771 por D. Ignacio Jordán de Asso y D. Miguel de Manuel Rodríguez. Con respecto a esta obra, Herr subraya su carácter profundamente histórico, en un momento en que esta materia sufría su primera gran eclosión(43), incubada desde los 
ya lejanos trabajos de Mayans, Flórez o Burriel durante la primera mitad de siglo.

El regalismo de Rubín, el apoyo que le prestaba el Consejo, y la actitud de este organismo ante la adopción del agustinismo en Murcia, son algunos de los factores que se habían manifestado con anterioridad a este plan de 1778, en el curso de la controversia suscitada por los dominicos murcianos a raíz del plan de estudios de teología y filosofía.

En efecto, una vez producida la expulsión de la Compañía, el frente común que hasta entonces presentaron frente a ella los dominicos y agustinos se escindió. Los dominicos vinieron a inclinarse por un tenaz conservadurismo que les convirtió en herederos del papel de defensores del ultramontanismo(44), aproximándose a la Santa Sede y defendiendo la doctrina de Santo Tomás como la ortodoxa; en este sentido, insistían en el peligro de la proximidad de las tesis agustinianas a los principios jansenistas. Los agustinos por su parte, continuaron defendiendo sus doctrinas sobre la gracia, y en buenas relaciones con la Iglesia de Utrecht y los jansenistas italianos y franceses. Las polémicas, en las que se disputaban el vacío dejado por la Compañía en el monopolio de la enseñanza, son la expresión de una divergencia de mayor amplitud que abarca toda Europa, y de manera especial, al mundo religioso italiano(45).

En Murcia se contaba con un precedente, ya en 1767. Cumplida la expulsión, los alumnos fulgentinos que asistían a las cátedras suaristas se pasaron a las aulas franciscanas. Celosos de perder el papel predominante que hasta entonces tuvieron, los dominicos murcianos levantaron pleito ante el Consejo, pretextando que los discipulos tomistas sufrian la persecución de los rectores de los seminarios de San Fulgencio y de San Isidoro, que pertenecian a la escuela escotista(46). No conocemos la decisión del Supremo Tribunal, si es que la hubo. Simplemente, parece que la cuestión languideció en Madrid, desde donde todavía en 1772 se solicitaba algún informe para el expediente.

Pero es el 24 de septiembre de 1774 (cinco días después de la publicación del plan de Rubín), cuando los dominicos reemprenden sus ataques, ahora enviando una representación al Consejo en la que se delataba el plan(47). Las acusaciones, sintomáticamente, iban dirigidas contra los autores: su conocimiento de las directrices gubernamentales les impedía arremeter contra el plan en su integridad, y menos aún directamente contra el obispo.

De este modo, imputaban a Berti el no admitir la necesidad de la gracia eficaz en todos los estados de la naturaleza criada. Con la cuestión del regalismo como telón de fondo de la polémica, más grave resultaba todavía la acusación de antirregalista que lanzaban contra este autor. Según los dominicos, el agustino italianọ defendía las tesis de la potestad 
civil del papa sobre los príncipes y de la inmunidad de las personas y bienes eclesiásticos, con origen en el derecho divino, "...por lo que es de temer, que este modo libre de opinar sea fomento de inquitudes y facciones perniciosas al Estado, como lo fue el que invento Luis de Molina (...) $y$ el de Cornelio Jansenio, no obstante de asegurar estaba conforme a la mente de San Agustin"..

Basándose en la condena que pesaba sobre sus Institutiones, los regulares también arremetían contra Juenin. De modo semejante a como lo hicieran en 1767 denunciando a sus enemigos por probabilistas y projesuitas, los dominicos creían ahora tocar la fibra sensible del equipo gubernamental presentando al seminario reformado como foco de incubación para las doctrinas opuestas a las regalías. El alegato terminaba solicitando del Consejo que la teología escolástica se enseñase por la "Suma" de Melchor Cano: tras tal petición se escondía su intento por mantener-a través de métodos indirectos-el control sobre la enseñanza del colegio.

Requerido por el Consejo, Rubín enviaba una enérgica respuesta contra la delación, fechada el 21 de febrero de 1.775(48). En opinión del obispo-que recalca haber elaborado el plan ateniéndose a la Real Cédula de 1768-, los regulares habian procedido de mala fè: Ios hechos estaban tergiversados en razón de sus intereses, pues «callan que sólo he propuesto en mi plan el tratado particular de Lugares teológicos, que escribió Gaspar Juenin, en el qual se halla compendiado con méthodo fácil, y acomodado a la inteligencia de los principiantes lo mejor que escribió el Docto Melchor Cano, sin las preocupaciones que se le notan a éste, y fueron comunes a su tiempo".

Este planteamiento moderado ante la figura del teólogo escolástico, favorable a los compendios y emparejado a su irritación ante unos regulares que pretenden inmiscuirse en cuestiones de estricta incumbencia episcopal, recuerda la postura de Mayans sobre el mismo punto(49). La obra de Cano es contemplada por Rubin desde una perspectiva superadora; no está dispuesto a admitirla, en ningún momento, desde las razones de autoridad que alegaban aquéllos. Lejos de despreciar al obispo de Canarias,cree que el conocimiento debe progresar sin estancarse en la interpretacion-siempre parcial y limitada-de un maestro en particular, por importante que éste sea.

Por lo demás, D. Manuel insiste en que el texto de Juenin está aprobado por el Consejo, al igual que la ortodoxia de Berti confirmada por Benedicto XIV. Las acusaciones sobre puntos de gracia han sido hechas sin probarlas en ningún momento. A propósito del primer autor, previó con agudeza el papel de defensores del ultramontanismo, que asumirian los dominicos en los años siguientes: "...quan reparable es, que unos Regulares Dominicos, quieran resucitar en España la persecución, que los Jesuitas movieron en Francia contra dichas Instituciones", y más adelante, 
"...mi veneración, y cordial afecto al Angélico Maestro, me obliga a decir que los Dominicos confunden sus opiniones particulares con las verdaderas, y genuinas del Sto. Doctor; y el sistema que han adoptado después de las famosas Congregaciones de auxiliis con el de Sto. Thomás».

La escolástica, degenerada a causa de los manejos interesados de las Ordenes, es la responsable de la desfiguración de las opiniones de San Agustín y Sto. Tomás. Una cosa es la enseñanza de la verdadera doctrina de los Santos Doctores, y otra bien distinta el aparato escolástico montado sobre ella.

Rubin defiende a Berti también en el tema de las regalías, pues tal autor expuso la cuestión sin tomar partido. En todo caso, la obra utilizada en el seminario es el compendio de Buzi, expurgado por el rey de cualquier opinión sospechosa. Es más, el obispo volverá contra los dominicos la acusación de antirregalismo, adjuntando a su informe un impreso de conclusiones difundidas en el convento murciano en 1765 , entre las cuales se establecia la doctrina de la potestad temporal del papa sobre los príncipes(50).

Justificando su postura personal, el prelado hace uso del recurso a la historia. Basa su juicio en los estudios de Noël Alexandre (otro conocido autor galicano tachado de jansenista), para afirmar que el origen de la difusión del ultramontanismo se halla en las falsas decretales. Y sin solución de continuidad, pasa a ocuparse del jansenismo:

"Qué comparación puede caber entre los autores de mi Plan, y Luis de Molina, de quien distan tanto como éste de San Agustín? Con qué fundamento temen los Regulares quejosos el Jansenismo en el P. Berti, cuio sistema de Gracia se aprobó por la Santa Sede, la misma que condenó al de Jansenio? Con más razón podía temerse, que los Regulares quejosos adopten las artes de los extinguidos, para encender en nuestra España el fuego de la discordia, que tantos estragos causó en otros Reynos".

El texto resume cuanto venimos observando. El sentido del equilibrio que manifiesta Rubín de Celis es el mantenido por nuestros hombres ilustrados: la autoridad dogmática de Roma permanece indiscutida, sin perjuicio para las regalías del soberano.

Este informe sentenciaba prácticamente la polémica, aunque los dominicos todavia enviaron otra representación el 25 de febrero de 1775(51). En efecto, previo informe del fiscal, que alaba la reforma del obispo y muestra una total coincidencia con los criterios que éste exponía en su defensa, el 16 de marzo el Consejo resolvia, quedando «...mui enterado y satisfecho de su acreditado celo Pastoral en promover la enseñanza pública (...) no obstante la delación (...) que como infundada ha desestimado el 
Consejo (...) al Prior y religiosos de dicho Convento, expresándoles que ha sido mui del desagrado del Consejo su representación contra el Plan de Estudios para dicho Seminario... $\times(52)$.

El predominio general del tomismo no había ahogado el desarrollo del agustinismo. Colocada la cuestión doctrinal al margen, era más importante para el gobierno apoyar a quien sabía su mejor agente reformista (el obispo), y sofocar cualquier brote de oposición-encarnada por los regulares -, máxime cuando ésta adquiria tintes antirregalistas.

La necesidad era recíproca: el obispo sabia que toda su fuerza se basaba en la ayuda que Madrid le prestase. Y con la resolución favorable al obispo y a su plan de estudios en 1775, tomaba cuerpo una alianza que no se quebrantaría hasta el cambio de circunstancias producido en tiempos de Carlos IV. Es este el momento (exactamente entre 1777 y 1783), en el que el seminario, a través de una serie de gracias concedidas por el consejo, alcanza la facultad de conceder títulos de Bachiller, a la sazón los más útiles y versátiles entre los expedidos por las universidades en aquella época(53).

En la concesión de cada una de las gracias, los ministros mostraron un parecer unánimemente favorable, salvo una solitaria excepción(54). La situación en la ciudad de Murcia era sustancialmente distinta. Al contrario que en el Consejo, la práctica mayoría de los componentes del cabildo municipal murciano, aun siendo partidarios de que se erigiese universidad en Murcia, se resistian a que el seminario desempeñase tal papel, pues no era institución creada-ni adecuada-para ese fin. Sin embargo, bajo la aparente lógica de estas argumentaciones, la lectura detallada de los expedientes(55) pone en claro la presencia en la politica local murciana de un grupo de oposición al cambio, con implicaciones ideológicas reaccionarias. Este sector, identificado con los regulares y sus intereses, actúan como portavoces en el nunca abandonado intento de estos últimos por ejercer en la ciudad el dominio sobre la enseñanza. El respeto por la autoridad real, que apoyaba firmemente al obispo, les hizo mantenerse en unos niveles moderados, eludiendo plantear ataques directos contra las nuevas realizaciones.

En la base de la postura sostenida por el Consejo podemos apreciar criterios francamente utilitarios. Como ya se dejo apuntado anteriormente, le resultaba más cómodo establecer los estudios universitarios (de acuerdo con sus planteamientos para difundir las "luces") en una institución ya existente y en la que podia mantener sin dificultades el control ideológico, a salvo de los grupos de oposición (ayuntamiento y regulares), que aventurarse creando una universidad de nueva planta. Finalmente, un último factor vino a incidir sobre tales presupuestos. Floridablanca, primer secreta. rio de Estado entre 1776 y 1792, presto su decidido apoyo a los progresos del seminario(56). 
De entre los documentos estudiados, destaca, por su extensión e interés, el que contiene el comentario que $\mathrm{D}$. Manuel Rubin de Celis hiciera a la bula papal de extinción de la Compañía de Jesús (publicado para su difusión en la diócesis murciana en 1773). Aparecen aquí, resumidos y enriquecidos, aquellos aspectos de su personalidad que venimos estudiando(57).

Tras reconocer la autoridad del pontífice en el gobierno de la Iglesia, califica la extinción de la orden como "suceso desgraciado" que encuentra su razón en la degeneración que había experimentado a lo largo de su trayectoria histórica. El ideal de una Iglesia universal, le hace salvarla por encima de sus religiones:

"...quiera Dios no lleguen a pensar, que sin ellas no se puede mantener la Iglesia. Este error se desvanece solamente con acordarse de los pasados siglos, que precedieron a las Religiones, sin las quales se conservó la Iglesia por trescientos años".

En correspondencia al ideal, el modelo-típicamente jensenista-ofrecido por la Iglesia primitiva, consecuencia lógica del recurso a la historia. Parejamente, la actitud ante los regulares encuentra su moderación, no en un odio visceral, sino como resultado de la serena mirada al pasado:

"...estamos muy distantes de presumir, que alguna religión, o todas ellas juntas son la Iglesia (...) no son ellas el todo, sino la parte (...) si todas ellas llegasen a faltar (lo que no permita Dios) no por eso había de faltar Iglesia".

El documento prosigue en un tono semejante, alternando el análisis histórico, para ir desgranando los errores en que habian caído los religiosos (en especial, la producción de una escolástica sin calidad y que sólo servía a los intereses particulares de cada Orden), con las alusiones a los SS. PP. (San Pablo, San Agustín y Santo Tomás). Como subrayábamos, esa moderación le hace reconocer la justa utilidad de las Ordenes religiosas y de los métodos escolásticos-parte integrante del patrimonio heredado por la Iglesia-, cuando son bien empleados.

El tema del jansenismo resultaba ineludible en un documento como éste. A tal efecto, realiza una serie de diferenciaciones, centradas en la defensa del antiprobabilismo, importancia de la gracia, y crítica de los criterios laxos, que-como fue común en los jansenistas españoles-cree derivados de las posiciones probabilistas. Sus criterios rigoristas le hacen condenar, por otra parte, el lujo excesivo, el trato familiar con las personas de sexo diferente, y defender la necesidad de la contrición en el sacramento de la penitencia. Todo ello viene matizado por la visión pesimista del mundo caracteristica en los jansenistas-implícita a lo largo de todo el documento. Vale la pena una larga cita: 
"No merecen más respuestas los que con voces, que pasan de temeridad, y suenan mucho a blasfemia, se atreven a decir, que los Jansenistas han conseguido un gran triunfo con la Bula de extinción: ¿adónde está su victoria? (...) No lo saben los que ignoran quánto dista el Jansenismo del Antiprobabilismo: no lo sabrán los que nunca quieran determinarse, y resolverse a conocer lo que pueden favorecidos de la Divina gracia (...) Los que no siguen tan divino exemplo se propasan a decir, que les mandan imposibles quando les proponen el dulce yugo de la Divina Ley: en esto mismo confiesan su tibieza, y falta de amor de Dios, cuya carga es suave para quien le ama, dura para quien no ama, según nos declaro San Agustín (...) gritan que a sus Personas todo es imposible, que es estilo, que es moda, que es inexcusable (...) Es imposible servir a dos Señores: es necesario romper con Dios, o el mundo: los que con opiniones peregrinas pretenden persuadir a sus Alumnos, que es posible complacer a estos dos dueños, podrán sólo divertir, o adormecer el clamor de su conciencia; pero cuando estubieren más embelesados con el sonido del organo, y la cítara, descenderán en un punto a los infiernos".

En la defensa de su postura religiosa, que insiste en separar del jansenismo doctrinal, se centra en el ataque al probabilismo:

"¿Quién de los dos será más Jansenista? El que consiente al hombre en el peligro, le dificulta el precepto; el que le aparta de las ocasiones le facilita más su cumplimiento: luego más lejos está del Jansenismo el que lleba lo seguro, que el que sigue lo probable".

A la vista de lo expuesto, Rubín de Celis puede ser calificado como jansenista en el sentido "histórico" que del término venimos haciendo uso. Por lo demás, su propia concepción, que contempla al jansenismo como una acusación en manos de probabilistas y jesuitas, está próxima a la que sostuvo en las Cortes de Cádiz el diputado liberal Joaquín Lorenzo Villanueva cuando subrayaba que su uso debía ser restringido a los defensores de las cinco proposiciones y que lo demás era un mito, un ufantasman, creado por los jesuitas para denigrar a quienes no aceptaban el probabilismo como sistema moral(58).

Favorecedor de innovación científica, caritativo y limosnero, vinculado a la Sociedad Económica de Amigos del País de Murcia, partidario de la difusión de la enseñanza y de la mejora del clero, Rubín fue auténtico hombre de su tiempo y obispo cilustradow(59).

El aspecto tocante a las relaciones entre el obispo y los indivíduos del seminario con la Sociedad Económica adquiere una relevancia excepcional. Herr señala tres instituciones particularmente importantes apoya- 
das por el gobierno para la introducción de las «luces" en España: periódicos, universidades y Sociedades Económicas de Amigos del País(60). La de Murcia, fundada en 1777, siguió una trayectoria muy similar a la de sus hermanas españolas. Pese a sus sinceros intentos en pro del fomento de las artes, la economia y la llustración, se vió siempre determinada por la cortedad de las rentas de que disponia. Es aqui donde Rubín aparece como protector de la institución: apoyó la academia de dibujo (a cuyo cargo se puso al escultor Saizillo), entregó 300.000 reales para premios en los distintos concursos (1781), e impuso 500.000 reales sobre la renta de tabacos a fin de cubrir las necesidades de las escuelas creadas. Años más tarde, esta política sería seguida por su sucesor en la sede murciana, D, Victoriano López Gonzalo, quien llegó a ser director de la Sociedad(61).

Las vinculaciones entre el clero murciano y la Económica no se circunscriben a los obispos. En este sentido, los datos iniciales con los que contamos confirman la vinculación indicada por Herr en el plano institucional y con carácter general para todo el pais. En el caso de Murcia, el análisis del círculo compuesto por el seminario de San Fulgencio (como centro universitario), la R. S. Económica, y el Correo Literario de Murcia, permite comprobar la íntima relación existente entre los indivíduos de estos organismos, que a su vez delimita el círculo ilustrado murciano. La referencia a tres personajes concretos resume cuanto apuntamos: Luis Santiago Vado, Mariano Garcia Zamora, y Francisco Meseguer(62), todos alumnos fulgentinos, relacionados con la Economica, y fundadores y asíduos colaboradores del Correo Literario. La lista, a buen seguro amplia, comprende a hombres como Gregorio Gisbert (socio nato y censor de la R.S.E.A.M.), José López Padilla (fundador de la misma), etc.

Rubín de Celis murió el 9 de agosto de 1784 , en el monasterio de los Gerónimos (La Ñora, Murcia). Carlos III lo hacia cuatro años después, y en 1789 estallaba la crisis revolucionaria francesa. El período que se extiende, aproximadamente, hasta esa fecha, conoció la máxima pujanza del seminario. Con un desarrollo casi perfecto de los planes de estudios, al tiempo que se duplicaba su número de alumnos (de 254 en el curso 1773-74, hasta 486 en el de 1799-1800, sin contar los cursantes de gramática), y sin problemas económicos, la institución cobró fama nacional. Apoyada por el gobierno, seguía con ello la marcha general del pais, dentro de un contexto de llustración sin las fisuras que se presentarian en tiempos de Carlos IV. Simultáneamente, las fuerzas locales de oposición permanecieron acalladas, ante la fuerza abrumadora que protegía al colegio.

Durante este lapso de tiempo, el desarrollo cultural del centro progresó también sin irregularidades ni sacudidas, manteniendo una línea de uniformidad en la trayectoria ideológica y cultural entre las disposiciones del obispo y su cumplimiento. Junto a los textos, un profesorado de calidad era la clave de la sintonía. Al corte con las ordenes religiosas, sucedio el 
nombramiento por Rubín de catedráticos nuevos, más acordes con el espíritu de la reforma que pensaba realizar. A través de éstos se establece nuevamente la relación con Valencia: son los casos de D. Tomás Fuentes, catedrático de humanidades, de D. Joseph Pérez, rector entre 1772 y 1780, $e$ incluso de $D$. Antonio Cavanilles, catedrático de filosofía, entre otros(63).

Así pues, la relación con el círculo valenciano (sin considerar la que, con carácter general, ejercio Mayans sobre toda nuestra llustración, que bien se manifiesta en los criterios moderados de Rubín de Celis), se concreta en el interés de los valencianos en el terreno doctrinal (agustinis$\mathrm{mo}$ ), en los textos y en los mismos indivíduos. Por esta vía podemos comprender aún mejor la naturaleza no radical, católica y equilibrada del pensamiento irradiado del seminario murciano.

Las relaciones de los fulgentinos con la Corte también resultan evidentes, como lo testimonia el apoyo del gobierno, la trayectoria anterior de Rubín de Celis o del propio D. Joseph Pérez, o la aparicion-ya en estos tiempos-, de algunos de los profesores o alumnos del seminario en las cátedras y canonjías de San Isidro64).

De ahí que (soslayando el terreno teologico, que hemos tratado anteriormente), fuese el obispo quien marcase en el seminario, con su propia actitud personal, abierta a la llustración, una línea favorable a la innovación científica y filosofica, que tenía su base en el intento de los ilustrados católicos por armonizar razón y fe, luchando contra los extremos que representaban la ignorancia y la superstición, o el racionalismo deísta y ateo. Así lo deducimos de la lectura de algunos impresos de conclusiones leídas en el seminario(65). Destaca en su contenido el conocimiento de las teorias y experiencias cientificas modernas, que se aceptan y defienden: Newton, Torricelli, Tycho Brahe, Copérnico... La historia misma es contemplada como una disciplina científica que sólo tiene validez si se apoya en una crítica severa de las fuentes. Alejada la escolástica, había sido po: sible abrirse a la Ciencia, sin caer en contradicciones con el dogma religioso(66).

\section{V}

La evolución sufrida por España durante el reinado de Carlos IV-con la Revolución Francesa como telón de fondo-, produjo una serie de consecuencias fundamentales, que Mestre ha resumido asi(67):

-Desprestigio del despotismo ilustrado. Se rompe la unión entre monarquía absoluta y reformismo, y el monarca deja de ser el motor de las reformas.

- Los reformistas evolucionan hacia el liberalismo, unos desde los principios ilustrados, otros por influjo revoluciona- 
rio, o a través de muchos vericuetos y partiendo desde el jansenismo.

- La crisis del Antiguo Régimen se ve agravada en su evolución interna por el desastre económico de las guerras provocadas por la Revolución.

-En el campo espiritual, se produce la ruptura entre revolucionarios y reaccionarios, con la Revolución como cuña separadora.

Cambian los personajes políticos y aparece una nueva generación jansenista, más radical que las precedentes: obispos (Tavira, Abad y La Sierra, López Gonzalo...), clérigos intelectuales (canonigos de la colegial de San Isidro y profesores de los Reales Estudios de San Isidro), religiosos (agustinos), y seglares (el grupo en torno a la condesa de Montijo). Asimismo, desaparecen progresivamente los antiguos focos jansenistas para ir centrándose en los ambientes madrileños.

La fuerza que adquiere el jensenismo en estos tiempos halla su explicación tanto en la propia evolución de las corrientes internas (con base en los planes de estudios universitarios implantados desde 1771, correspondiendo con la actitud más abierta de los agustinos), como por el influjo de los acontecimientos europeos, entre los que destacan el Sínodo de Pistoya y la Constitución Civil del Clero (predominio, en cada caso, del episcopalismo y del galicanismo).

La radicalización aparecía también en el campo de la infiltración del pensamiento ilustrado francés. En este contexto, con una antipatía creciente ante el Santo Oficio, se perfilan acusadamente las relaciones entre ilustrados y jansenistas. Superadas las diferencias de los tiempos pasados, ahora las dos corrientes se habian acercado en una línea unificada frente a los conservadores que se les oponían. Jovellanos es aquí el eslabón más importante.

Por su parte, los conservadores, aglutinados bajo la consigna de combatir la llustracion racionalista francesa, identificaban los intereses eclesiásticos y religiosos con los planteamientos temporales de la Iglesia, vinculada a la estructura político-social del Antiguo Régimen. De este modo, los apologetas considerarán necesaria la unión del Altar y del Trono para la defensa del catolicismo (ataques al liberalismo).

La postura política sostenida por el Estado frente a la radicalización general tuvo sus alternativas. Tras las medidas restrictivas tomadas por Floridablanca en el intento de detener la infiltración de propaganda revolucionaria, el ascenso de Godoy vino acompañado por una mayor libertad de prensa. Los años subsiguientes presencian el ascenso del jansenismo, que tuvo su climax en el llamado "cisma de Urquijo". La caída del ministro precedió a la aceptación de la bula "Auctorem fidei" y al comienzo de la 
persecución de los jansenistas, protagonizada por el ultramontanismo y la Inquisición, a la sombra del poder político. Sin embargo, la tácita tolerancia gubernamental (que veía en los jansenistas un punto de apoyo seguro en la defensa de las regalías) posibilitó que el movimiento no desapareciese(68).

El cambio en la situación general tuvo sus efectos sobre el seminario de San Fulgencio. La evolución del colegio durante este periodo se vería presidida por el cada vez más tibio apoyo del gobierno en el terreno cultural, que derivó finalmente en la represión, en coincidencia con la ruptura entre el poder absolutista y los reformistas. Paralelamente, el centro, en su conjunto, se orientó hacia posturas más radicales.

Dos aspectos cabe diferenciar en el análisis del período que se extiende hasta 1808 (reinado de Carlos IV y pontificado de Victoriano López Gonzalo). El primero es el cronológico. Aquí, las informaciones difieren según se trate de los superiores y profesores del seminario, o de los religiosos y oponentes en general(69). En cuanto a los primeros, coinciden en señalar un correcto funcionamiento de los planes de estudios hasta 1790-1795, en que aparecen elementos extremos. Los segundos, sitúan cualquier época de esplendor del colegio con anterioridad a las reformas de Rubín de Celis. Es decir, que sobre un sustancial continuismo en la enseñanza del pensamiento jansenista e ilustrado entre 1774 y 1808, al comenzar la década de 1790 se hace patente la infiltración del pensamiento radical, tanto filosofico como religioso, en relación con los acontecimientos producidos en el extranjero (Revolución Francesa, Sínodo de Pistoya y Constitución Civil del Clero, ya citados).

Sin embargo, conviene resaltar un hecho fundamental: la evolución hacia el jansenismo radical y, después, hacia el liberalismo, tuvo sus primeras raíces en los mismos textos empleados en el seminario desde los tiempos de Rubín de Celis. Su sucesor, D. Victoriano López Gonzalo, mantuvo los mismos textos e introdujo algunas reformas que apuntaban la radicalización de posturas, como veremos a continuación.

El segundo aspecto, íntimamente relacionado con el primero, atañe directamente a la naturaleza de las doctrinas que durante este periodo hallaron cobijo en el interior del seminario. La documentación utilizada(70) confirma la difusión en el colegio de las obras de Tamburini, Sínodo de Pistoya, etc., así como de los filosofos racionalistas franceses: Voltaire, Rousseau, Diderot y D'Alembert son citados en algunas ocasiones. Sin embargo, el conocimiento de otros autores racionalistas hubo de ser anterior a 1790, como se vio en el apartado IV. En este grupo se englobarían las obras de Montesquieu, Puffendorf, Condillac, e incluso las "Instituciones políticas" del barón de Bielefeld, alguno de los cuales era citado en las clases. 
No obstante, si hemos de dar crédito a las acusaciones de los regulares, las doctrinas que circulaban en el seminario eran ciertamente extremas:

-Ridiculización de las ceremonias y, en general, crítica a las procesiones y formas de religiosidad exterior, «llamando Saynetes espirituales a las (procesiones) del Viernes Santon. -Ataques a la Curia y al Papa, a quien llamaban "Obispo de Roma y nada más". A propósito de su infalibilidad, decían los regulares que «cuando hablaban de la precisión de algún reloj, decian que era más infalible que el Papan.

-En tono similar, se describen los ataques contra los regulares y contra el método escolástico, extendido al método silogístico, al latín e incluso al rechazo de Santo Tomás y de Aristóteles. En algunos profesores, se llegaba a no respetar ni seguir el método y autores de los planes oficiales.

Junto a estas doctrinas, puramente jansenistas, se plantea la oposición al absolutismo, de tal manera que la evolución hacia el liberalismo y el constitucionalismo en los indivíduos del seminario es un proceso evidente ya hacia el cambio de siglo.

No faltaron los problemas con el Tribunal de la Fe. Como dicen los regulares y confirma Llorente, en 1800 el obispo López Gonzalo fue delatado y procesado como jansenista, al haber permitido defender en el seminario algunas conclusiones relativas a la aplicación del valor del sacrificio de la misa y sobre los milagros. A través de una enérgica representación, el obispo consiguio detener el proceso abierto contra su persona(71). Anteriormente (1788), también fuerǫn delatadas las conclusiones sostenidas por Ramón Campos, que contenian la negación de la infalibilidad papal(72).

La difusión de las nuevas corrientes en el seminario contó con factores que la propiciaron. Los mismos superiores del seminario creían que éste tenia licencia para retener libros prohibidos. La procedencia de estas obras hubo de ser varia, aunque en una ocasión se indica expresamente su origen en Cádiz(73). También debe ser considerado el contacto secularizador entre alumnos internos y externos, a causa de la gran masa de manteístas que acudian a las aulas del seminario, asi como la actitud de los profesores más radicales. Sin embargo, la aceptación de las teorias extremas que hemos descrito sólo se dio precisamente entre el reducido grupo de tales profesores. Caracteres distintos, mucho más moderados, se derivaban de la línea oficialmente sostenida en los planes de estudios, cuyo primer protagonista va a ser el obispo, y que es la seguida por la totalidad de los superiores y la mayoría de los catedráticos. Esto es así hasta el punto de que $\mathrm{D}$. Victoriano no dudó en expulsar a todos aquellos que transgredieron los planes, adentrándose en la senda del deísmo o del 
ateísmo(74). El que la enseñanza de las nuevas ideas introducidas al margen de aquéllos se produjese en reuniones privadas $y$-salvo raros casos-por vía distinta de la académica, confirma cuanto exponemos. No cabe duda de que eran conocidas por todos los fulgentinos (alumnos y profesores), y de que religiosidad y posturas jansenistas, conocimiento de los "filosofos» francéses y evolución hacia el liberalismo se presentarán unidas en los indivíduos en particular y en la institución en general. Pero los liberales salidos de San Fulgencio, en sus casos más significativos, heredaron la postura de los ilustrados católicos: conocer el deísmo y el ateismo significaba, casi siempre, refutarlos.

En la dirección del seminario, el prelado continuaba teniendo el papel más relevante. Victoriano López Gonzalo (obispo de Cartagena entre 1789 y 1805), siguió con la política de reformas emprendida por Rubín de Celis. Director de la Sociedad Económica de Murcia, reformará el plan de estudios de cánones, conseguirá del Consejo la gracia de que los seminaristas teólogos pudiesen optar a los exámenes de grado mayor, y redactará las constituciones de 1803, en las que incluía el plan de gramática latina que otorgó en 1801(75). En su obra reformadora, destacan precisamente las nuevas constituciones, por cuanto recogen-en lo cultural-todas las disposiciones anteriores sobre estudios (o introducen nuevos elementos pedagógicos, totalmente abiertos), a la vez que dan al seminario una nueva estructuración, más compleja y acorde con los nuevos tiempos, sin hacerle perder por ello su carácter de auténtica institución conciliar.

Las coincidencias con Rubín de Celis son más extensas, en especial en materia de estudios, terreno éste en el que mantuvo los textos vigentes desde 1774. El jansenismo y la apertura ante la ilustración científica están también presentes en su postura personal: desprecio de la moral laxa y de la escolástica, unido a iguales sentimientós frente a las novedades doctrinales o los entretenimientos profanos. Se advierte, eso sí, un matiz más ra. dical en sus opiniones(76), que nos permite enmarcar la reforma del plan de cánones. Se introduce en él la obra de un autor más claramente jansenista: las Instituciones canónicas, de Domingo Cabalario, en sustitución de los textos de Selvagio y Del Vaulx, que se suprimian por lo inútil de algunas partes del primero y la excesiva indulgencia del segundo. Dos nuevos textos se consagran en las constituciones de 1803: el catecismo del obispo de Soissons, Francisco de Fitz-James (jansenista), y el Compendium elementorum mathesae universae (in usum studiosae Juventutis adornatum), de Christian Wolf (ilustrado)(77).

Pero si la controversia sostenida con los dominicos en 1775 marcó el comienzo del ascenso del seminario, merced al'apoyo estatal, la que se levantó a raíz de la aprobación de las constituciones señalaría el punto final del proceso: Por otra parte, es en su desarrollo donde mejor expuso López Gonzalo sus planteamientos personales. 
La cuestión se enmarca en el cambio de circunstancias politicas que se produjo en 1800 (caída de Urquijo y comienzo de la ofensiva antijansenista). Todavia dos años antes, el Consejo había aprobado sin ningún problema la reforma del plan de cánones. Siguiendo el tramite normal, las nuevas constituciones, una vez remitidas a Madrid por el obispo, fueron informadas favorablemente por los fiscales, y aprobadas por el Consejo, con fecha de $1 .^{\circ}$ de diciembre de 1800.

Días más tarde, Urquijo era destituido de su cargo, y el 27 de diciembre, el rey enviaba el texto de las constituciones a un indivíduo de su confianza. El informe que este censor (anónimo) remitió(78) dirigia sus críticas, básicamente, contra los planes de teología y derecho. Con criterios tradicionalistas cargados de nacionalismo, recurre a los grandes teólogos españoles del siglo XVI, para acusar de galicanismo a Juenin y a Berti de "formar cierta escuela" siguiendo todas las opiniones agustinianas. Las objeciones son aún más graves en cuanto se refiere a Cabalario, a causa de su desprecio por la Inquisición, reducciones a la autoridad papal y ponderación excesiva de los abusos de Roma; asimismo, tras colocar a este autor en posiciones próximas a las de luteranos y calvinistas, no le parecen adecuados los ataques que dirige contra los regulares, ni el énfasis que pone en describir los primeros siglos de la Iglesia.

El 10 de mayo de 1802, contestaba el obispo a los argumentos de su crítico(79). Todo el informe de López Gonzalo se ve presidido por la extrañeza-mezclada con tintes de amargura-que siente ante lo ocurrido: el plan literario que había remitido inserto en las constituciones habia sido aprobado por el Consejo hacía ya más de veinte años. Sobre los cursos de teologia, López define al censor como "enteramente huésped en materias teológicas", y opone al nacionalismo de su contrario, la concepción que él tiene de una Iglesia universal, no sujeta a las barreras impuestas por uno u otro Estado:

"Quisiera yo que quando se trata de cosas pertenecientes a la Yglesia que cuenta entre sus caracteres el de Católica o universal a una congregación que es de todos tiempos y Payses, (...) según enseña San Pablo (...) Quisiera yo, digo, que nunca se oyera hablar de Teólogo español, de Juventud española, sino de teólogo cristiano, de Juventud cristiana".

Esta visión exige la separación entre la potestad papal y la real, entre Iglesia y Estado, que explicaria la defensa que hace a continuación de los cuatro artículos de la declaración del clero galicano de 1682.

Por otra parte, la obra de Berti-prosigue-se ajusta exactamente a la doctrina de San Agustín, y además lo hace con una admirable exposición dogmática alejada de escolasticismos estériles. Tanto en esta obra como en la de Juenin, la base fundamental es la Sagrada Escritura, 
seguida de los Santos Padres, concilios y teólogos y comentadores más célebres.

En cuanto a la obra de Cabalario, el obispo insiste en que debe dejarse aparte el juicio personal sobre la vida del autor, y recuerda que la obra ha sido aprobada por el rey y por la Inquisición.

Los párrafos finales del documento, siempre repletos de amargura, contienen las advertencias que hace un hombre ya cansado y desengañado:

"¿Querrá el Consejo que se vuelvan a entronizar las falsas decretales, origen de tantos daños causados al Sacerdocio y al Ymperio? ¿Querrá que a la sombra de estos supuestos y perniciosos documentos se vuelvan a concentrar todas las clases de autoridad en una sola mano? ¿Querrá que a fuerza de exaltar desmedidamente las prerrogativas de la Santa Sede se desconozcan otra vez los derechos del Episcopado y de la Soberanía?..: Descartemos norabuena las peligrosas novedades, resistamos a los innovadores que a título de reforma quisieren alterar la unidad de la Yglesia, y a privar a la Silla Apostólica de la primacia y respeto legítimo que le es debido: pero resistamos también a la pérfida astucia de los que so color de precaver este inconveniente quieren cerrar la puerta a toda reforma, a los que sembrando temores vanos en las almas timoratas y débiles tiran a perpetuar los abusos, y a pretexto de establecer la autoridad de la Santa Sede (...) quieren realmente acreditar las máximas favorables a la ambición y codicia de los curiales...".

Estos párrafos (perfecto resumen de la mentalidad de López Gonzalo), no surtieron efecto: las constituciones, publicadas en 1803, fueron totalmente mutiladas en su parte literaria. La Corona había anulado, con efectos que serian definitivos; los textos y la obra que ella misma habia sido la primera en apoyar, veinticinco años antes. El hecho no deja de estar cargado de simbolismo: se había roto la antigua armonia-y López era plenamente consciente-vivida en tiempos de Carlos III.

A partir de ese momento, el seminario comienza su caída, en todos los órdenes. Una sublevación, protagonizada por los mateístas al promulgarse las constituciones (1804), hizo que el propio obispo se pronunciase por la supresión de la cátedra de derecho civil y la restitución del seminario a su estricto carácter conciliar. Entretanto, el Estado retoma sus antiguos ímpetus centralizadores, con la promulgación del Ilamado "plan Caballe- 
ron, (1807), que había de aplicarse también al seminario murciano. Este hecho suponía la abolición de la vigencia oficial de cualquier plan de estudios anterior, incluidos los de 1774 y 1778 . En virtud de la misma ley, cesaba el colegio en la facultad de conferir grados mayores, y en el privilegio que permitia a sus seminaristas télogos acceder a grado mayor. Aprovechando el momento, el nuevo obispo José Ximénez suprimía todas las cátedras de derecho, civil y canónico. Todas las reformas comenzadas, no ya con Rubin de Celis, sino incluso algunas de las realizadas por Belluga, habian sido borradas en apenas unos meses(80).

Pero el fruto de la época de reformas no habia desaparecido. En la primera década del nuevo siglo, el flujo de antiguos alumnos fulgentinos hacia la Corte se hace más intenso. Allí los vemos en las canonjías de San Isidro o en el círculo de la condesa de Montijo, relacionados con personalidades de la talla de Jovellanos. Algunos de ellos, como Antonio Posadas Rubín de Celis o Diego Clemencín, tuvieron destacado papel en las primeras etapas del liberalismo español. Se cumplía así en el seminario de San Fulgencio la evolución hacia el constitucionalismo desde los planteamientos jansenistas y los criterios de los ilustrados católicos. La mejor prueba que podemos aportar son las "Proposiciones sobre la armonia de la religión católica", leídas en el colegio en 1.821, cuyo fin era "manifestar la perfecta conformidad de nuestra Constitución con la Religión católica y el recíproco auxilio que se prestan,(81).

\section{NOTAS}

(1) Vicente DE LA FUENTE, Historia de las universidades, Colegios y demás establecimientos de Enseñanza en España. Madrid, 1889, tomo IV, pp. 144-146.

(2) El único trabajo que se ha ocupado del seminario ha sido el de F. GIMENEZ DE GREGORIO, "El colegio-seminario conciliar de San Fulgencio", en Anales de la Universidad de Murcia, vol. VIII, años 1949-1950. Es muy valiosa la aportación de fondos documentales para el estudio del seminario.

(3) E. APPOLIS, Les jansenistes espagno/s. Sabodi, Bordeaux, 1.966 p. 5.

(4) A. MESTRE, "Religión y cultura en el siglo XVIII español», en Historia de la Iglesia en España, B.A.C., Madrid, 1979, tomo IV p. 641.

(5) Ibid., pp. 641-646.

(6) Ibid., p. 648. Id. "Los humanistas españoles del XVI en la religiosidad de los ilustrados valencianos”, en Hispania Sacra, XXXIII, (1981), pp. 229-273.

(7) Ibid., p. 657.

(8) A. MESTRE, Ilustración y reforma de la Iglesia, Valencia, 1968, pp. 451-454.

(9) F. MARTIN HERNANDEZ, Los seminarios españoles: Historia y pedagogia, 1.563-1700. Ed. Sigueme, Salamanca, 1964, Caps. IV y V. 
(10) Desde principios de siglo, estas escuelas eran la suarista, tomista y escotista. En razón de la pertenencia, los alumnos acudian, respectivamente, a los conventos de la Anunciata (jesuitas), Santo Domingo (dominicos) e Inmaculada Concepción (franciscanos).

(11) Archivo Municipal de Murcia (A. M. M.) «Escritura definitiva de fundaciones. (Roma, 18 de noviembre de 1741). Reimpresa en Murcia en 1777, 76 pp. Las Constituciones de Belluga, otorgadas en 1707, en Archivo Histórico Nacional, Madrid, (A. H. N.), Consejos, Leg. 5.496.

(12) Escritura cit., punto 144, p. 46. Floridablanca confirmó personalmente haber sido el primer catedrático del seminario. Archivo General de Simancas (A. G. S.), Leg. 971 antiguo. Expte. El rector y seminario... (1781), nota autógrafa de 29 de octubre de 1781.

(13) V. DE LA FUENTE. loc. cit.

(14) R. KAGAN, Universidad y sociedad en la España Moderna, Tecnos, 1981, p. 230 y ss.

(15) F. y J. MARTIN HERNANDEZ, Los seminarios españoles en la época de la llustración, C. S. I. C. Madrid, 1963. p. 198 y ss. Significativamente, dos dias antes el gobierno habia decretado la extinción de las cátedras y autores de la escuela jesuistica en todas las universidades y estudios del Reino.

(16) Este plan nunca se redacto, pero si se hizo el destinado a las universidades, obra de Mayans en 1767. A. MESTRE, «Religión y cultura...», pp. 671-672.

(17) Algunos datos biográficos en P. TEJERA, Biblioteca del murciano o ensayo de un diccionario biográfico y bibliográfico de la literatura en Murcian, Madrid, Tip. Rev. de Archivos, 1922. Tomo II, p. 164 y ss., asi como en dos sermones fúnebres que le dedicó la R. S. E. A. P. de Murcia, en 27 de noviembre de 1784 y $1 .^{\circ}$ de diciembre de 1831, pronunciados, respectivamente, por Fr. Antonino Galvez y por D. Leandro Alvarez (A. M. M.). Rubin de Celis nació en el valle de Cabuérniga (Santander), posiblemente a principios de siglo. Se doctoró en derecho civil y canónico en la universidad de Valladolid. Coadjutor vicario y provisor interino, sucesivamente, en los obispados de Murcia (con el obispo Mateo López, 1742-1752) y Palencia. Juez Inquisidor y, más tarde, obispo de Valladolid, desde donde pasó a ocupar la sede murciana.

(18) Elogio fúnebre de Galvez, ya cit., p. XLIV, nota 4. Este viaje hubo de tener lugar en los años anteriores a 1740, año del fin de la estancia de Jacquier en el citado Colegio. Por otra parte, es el momento en que Rubin ya ha terminado sus estudios, pero aún no ha pasado a ocupar su primer destino.

(19) Plan de estudios para filosofia, teología escolástica y teologia moral (16 de septiembre de 1774). Plan de estudios para derecho civil y canónico (16 de septiembre de 1778). Ambos en A. H. N., Cons., leg. 5496 Expte... sobre aprobación de las Constituciones o Estatutos que ha formado para el gobierno del seminario conciliar de San Fulgencio... (Murcia, 1800).

(20) La primera edición es de Roma (1757, 6 tomos). Jacquier era francés, religioso mínimo (1711-1788). Consumado matemático, conocedor de las lenguas antiguas (hebreo y griego), penetró en el terreno del cálculo integral y de la astronomia. Divulgador de Newton (Comentario sobre Newton, 1739), catedrático de Sagrada Escritura y de física experimental en el Colegio Urbano de Roma, y miembro de multitud de academias europeas. (Biografía eclesiástica completa. Madrid-Barcelona, 1856, tomo X, p. 499).

(21) R. HERR, España y la Revolución del siglo XVIII. Madrid, Aguilar, 1964. pp. 141-142 y 144. Oficialmente apoyada por el Consejo para su introducción en las universidades, alcanzo al menos seis ediciones antes de 1805. El Archivo Histórico de Orihuela (A. H. O.) posee varias de ellas, como la de Venecia (Occhi, 1773) y dos de Valencia (1778 y 1782, por B. Monfort).

(22) Teólogo, oratoniano (1650-1713). Sus Institutiones theologicae ad usum seminariorum levantaron vivas polémicas en Francia, en las que fue acusado de jansenismo. La campaña culminó con la prohibición de la obra "donec corrigatur", efectuada por Clemente XI en 1708 (Dictionaire de Theologie Catholique, Paris, 1925, tomo VIII, 1719). El tratado elegido por Rubin es el De Locis Theologicis liber singularis ex institutionibus ad usum seminariorum, primer tomo de las referidas Institutiones... El A. H. O. posee ejemplares de la edición valenciana de 1771 (Monfort).

(23) DANIEL CONCINA. Teólogo dominico (1686-1757). Gozó de la protección de Benedicto XIV, pero Rávago hizo lo posible por impedir su difusión. 
(24) Librorum XXXVII De theologicis disciplinis accurata synopsis, quam ad usum seminarii auximatis concinnavit... F. Hieronymus Maria Buzius agustinianus... El A. H. O. conserva un ejemplar del $4 .^{\circ}$ y último tomo, impreso en Roma «sumptibus remondinianis, en 1759. Juan Lorenzo Berti era un teólogo agustino italiano (1696-1766). Su obra De theologicis discip/inis se publicó en Roma entre 1739 y 1745. Denunciada como jansenista, Benedicto XIV aprobó la ortodoxia de la obra (D. T. C., tomo II, p. 795; Cf. B. E. C., tomo II, p. 632).

(25) A. MESTRE, «Religión y cultura...», p. 671.

(26) Por otra parte, la Real Cédula sobre "erección de seminarios conciliares", prohibía la adopción de sistemas particulares, reduciéndose a un justo límite las sutilezas Escolásticas, prohibiendo la enseñanza de interpretaciones distintas a las de San Agustin o Santo Tomás. Años más tarde, el obispo López Gonzalo utilizará claramente la denominación «teologia dogmática». (A. H. N., Cons. Leg. 5.496, Expte. sobre las Constituciones,... 1800).

(27) Todavia en 1790, Jovellanos-en el plan de estudios que propuso para el Colegio Imperial de Calatrava-abogaba por la implantación de autores vigentes con un decenio largo de anticipación en Murcia: Heinecke, Berti, Selvagio, Wolf, Jacquier, Gravina, Vinnen, Asso y Manuel, etc. (J. SARRAILH, La España ilustrada de la segunda mitad del siglo XVIII, F. C. E., México-Buenos Aires, 1.957, pp. 156-157).

(28) A. MESTRE, llustración y reforma..., p. 446. Aunque las universidades se inclinaron por la tendencia tomista, favorecida por el Consejo, no se obstaculizó el desarrollo del agustinismo.

(29) Jbid., p. 410. La opinión de Mayans respecto a Concina no era muy favorable.

(30) Uno de ellos, de 1778, en A. H. N., Cons., Leg. 5.496.

(31) En 1781, Rubín de Celis puso un pasante para explicar griego a los alumnos más adelantados. (A. H. N., Cons., leg. 5.496, Diligencia de visita... 1815).

(32) Básicamente, el alumnado de esta cátedra era los seglares manteístas. En su esfuerzo por preservar el caracter conciliar del seminario, los prelados murcianos prohibieron repetidamente la concurrencia a estas aulas de los colegiales seminaristas (internos, becas de gracia o porcionistas), que se educaban para la carrera eclesiástica. (A. H. N., Cons., Leg. 5.496, Diligencia de visita...).

(33) Estas incompatibilidades no existieron en la mente de Rubín, que más bien consideraba a los dos planes de estudios como componentes de un todo sin soluciones de continuidad.

(34) A. MESTRE, Ilustración y reforma..., p. 344.

(35) Plan de estudios de derecho (1.778), loc. cit.

(36) J. Lorenzo Selvagio (1728-1772), eclesiástico, catedrático de derecho civil y canónico, arqueólogo.

(37) Vallensi, andrea, (vulgo, del Vaulx). Paratitla sive summaria et methodica explicatio decretalium D. Gregorii papae IX. Antuerpiae, apud Petrum Bellerum, 1660. La edición consultada en A. H. O.

(38) Aunque no se colocase ninguna obra de Van Espen, nótese la correlación existente entre su predominio en el campo de la enseñanza universitaria del derecho canónico y el estabiecimiento de textos que defienden el rigorismo moral (A. MESTRE, "Religión y cultura...", $p$. 674). En Murcia, al conocimiento de Van Espen se une el uso de Juenin y Concina.

(39) Arnold Vinnen, latinizado Vinnius. Jurisconsulto holandés (1588-1657), profesor de Derecho Romano en la universidad de Leyden. Este texto ya fue elegido por Belluga para esta cátedra del seminario. Mayans leyó y apreció en su juventud los Arnoldi Vinii comentarii Institutionum Imperialum (A. MESTRE, Ilustración y reforma... pp. 41-42). El A. H. O. conserva una edición de Valencia, de 1767, por Monfort, completada con anotaciones de Heinecke.

(40) Gravina, J. V. (1644-1718). Jurisconsulto y literato, profesor de derecho civil y canóni$\mathrm{co}$, miembro de la Academia de los Arcades y fundador de la de Quirini (1711). La obra puede consultarse también en el A. H. O. (Originum iuris civilis, libri tres, et de romano imperio, liber singularis. Nápoles, 1778, Ex typographia Haeredum Pittanti, 4 volúmenes en un tomo. Otra edición, también veneciana, en 1758). 
(41) J. G. Heinecke (Heineccius). Jurisconsulto y filósofo alemán (1681-1741). La obra de Marín y Mendoza-a la sazón catedrático de esta disciplina en los Reales Estudios de San Isidro-, son los Joan Gotlieb Heineccii Elementa iuris Naturae et Gentium, castigationibus ex catholicorum doctrina et Juris Historia aucta, ab Joachimo Marin et Mendoza, J. N. et G. in regio matrit. Lyceo Prof. Matriti: ex Officina Emmanuel Martini. Anno 1776 (en 4. ${ }^{\mathrm{a}}$ ). Cfr. J. SEMPERE Y GUARINOS, Ensayo de una biblioteca española de los mejores escritores del reinado de Carlos III (Madrid, 1785-1789, volumen IV, pp. 9-11).

(42) La expresion "derecho natural y de gentes", que circulaba por Europa desde hacia más de cien años (en las universidades católicas y protestantes), lejos de tener relación con las teorias rousseaunianas, significaba el concepto que del derecho natural tenían los ilustrados católicos, acomo conjunto de leyes dimanadas de Dios y participadas a los hombres por medio de la razón naturalı. El monarca insistió en que la ensef́anza de esta materia debía demostrar "la unión necesaria de la Religión, de la Moral y de la Política". El derecho de gentes consistía en los mismos principios aplicados en las relaciones entre los Estados. El cambio en las circunstancias políticas hizo que esta ensenanza fuese suprimida y prohibida el 31 de julio de 1794. Sin embargo, el interés por ella, sembrado en los años precedentes, no disminuyó ( $R$. HERR, op. cit., p. 145; 310-311).

(43) Ibid., p. 282. Cf. J. SEMPERE Y GUARINOS, op. cit.,vol. I, p. 147-154.

(44) R. HERR, op. cit, p. 141-144.

(45) A. MESTRE, "Religion y cultura...», p. 676.

(46) A. H. N., Cons. leg. 5.495. Representación del Prior de Santo Domingo de la Ciudad de Murcia... 1767.

(47) A. H. N., Cons. Leg. 606-607. Representación del Prior y Religiosos del combento de Santo Domingo de la Ciudad de Murcia... (24 septiembre 1774).

(48) A. H. N., Cons. Leg. 606-607 Informe de Rubin de Celis (21 febrero 1775).

(49) A. MESTRE, Ilustración y reforma de la Iglesia, pp. 340-342.

(50) Este impreso en el citado legajo 606-607 del A. H. N.

(51) Ibid.

(52) Ibid. En Valencia, el resultado de la controversia tuvo gran interés para los partidarios del agustinismo. Mayans copió integramente la resolución del Consejo. (B. A. H. M., 650, autógrafo de Mayans).

(53) - Real Provisión de 22 de agosto de 1777, por la que se incorporaban los estudios del seminario de San Fulgencio a las universidades de Orihuela o Granada, declarándose válidos los que en aquél se efectuasen (de teología y filosófía) para la obtención de grados en dichas universidades. No se facultaba para la obtención de grados mayores (sólo el de Bachiller), ni tampoco se comprendia a los manteístas (y sí a los colegiales y porcionistas).

-Real provision de $11^{\circ}$ de diciembre de 1781 , extendiendo la gracia anterior a los cursantes de derecho civil y canónico desde el plan de 1778, e incluyendo a todo el alumnado.

-Real Cédula de 22 de julio de 1783, por la que se concedia al seminario la prerrogativa de conceder a sus alumnos el grado de Bachiller, sin más requisito que cumplir lo dispuesto legalmente en materia de matrículas y exámenes por el Consejo para todas las universidades.

(54) Durante las discusiones en el Consejo sobre la concesión de la gracia de 1781, el ministro Juan Acedo Rico se opuso a ella, mostrando argumentos de marcado matiz conservador.

(55) A. H. N. Cons. Leg. 5.496, varios expedientes entre 1777 y 1783.

(56) A. G. S. Leg. cit. El expediente de 1783 fue promovido por orden de Moñino (A. H. N., Cons., Leg. 5.496).

(57) El documento, impreso, está fechado el 3 de diciembre de 1773 (en A. M. M.).

(58) A. MESTRE, "Religión y cultura...», ṕ. 665.

(59) P. TEJERA, loc., cit., le imputa la realización de dos traducciones: un Tratado de cánamo, de M. Marcandier (Madrid, 1774, por Sancha), y una Historia de los progresos del entendi- 
miento humano en las ciencias exactas y en las artes que dependen de ella, de $\mathrm{M}$. Saverien (Madrid, Sancha, 1775). HERR, op. cit., cita tanto las traducciones como su papel de obispo, pero en ningún momento afirma si se trata del mismo personaje 0 de dos distintos. Por su parte, SARRAILH, op. cit., lo da como traductor de Saverien, y le atribuye otro opúsculo: Junta que en casa de $D$. Santos Celis tuvieron ciertos eruditos a la violeta, y parecer que sobre dicho papel ha dado el mismo D. Manuel Noriega... (publicado en Madrid en Los eruditos a la violeta, 1781). Este opúsculo confirma casi con total seguridad la identidad de Rubin de Celis como autor de estas traducciónes, puesto que D. Manuel Noriega no es otro que D. Manuel Rubín de Celis Noriega, rector que fue del seminario en varias ocasiones.

(60) R. HERR, op. cit. p. 129.

(61) Reseña histórica de la R. S. E. de Amigos del País de la Ciudad de Murcia (A. M. M.).

(62) Vado fue conocido como matemático, García Zamora como predicador, y Meseguer como médico y hombre polifacético. Sobre sus biografías, Cf. TEJERA, op. cit.

(63) Cuatro cartas de Tomás Fuentes a Gregorio Mayans revelan la amistad que unia a Fuentes con los hermanos Mayans (Archivo Ayuntamiento de Valencia, fondo Serrano Morales, cajas 19 y 60 . Agradecemos a D. Antonio Mestre estas referencias). En cuanto a Pérez, arcediano de Chinchilla, pertenecia al gremio y claustro de Valencia. Anteriormente, aparece en el círculo de valencianos en la Corte, en donde se presentó como candidato al nombramiento de director de los Reales Estudios de San Isidro. Gregorio Mayans, Epistolario VI. Mayans y Pérez Bayer. Estudio preliminar por A. MESTRE, p. LXII-LXIII. Los regulares, en 1815, atribuyeron la iniciativa de las reformas a este personaje. Aunque sin lugar a dudas exageraban, Pérez hubo de ser el más eficaz colaborador de Rubín de Celis en la tarea reformista, y puente directo de la relación con los valencianos, tanto en dicha ciudad como en Madrid.

(64) El primer fulgentino que aparece en una canonjia de San Isidro fue Antonio Puyal, en 1777. El flujo sería cada vez más fuerte. (A. H. N., cons., Leg. 5.496, Diligencia de visita...).

(65) Conclusiones..., (A. H. N., Cons., Leg. 5.496).

(66) En el campo de la psicología, el deseo de armonizar razón y dogma les hace caer en la formulación de teorias artificiosas y apriorísticas. Esta tara se deriva del postulado previo que se establece para el estudio psicológico: la defensa ante los impios de la inmortalidad del alma (identifican mente y alma). En otros terrenos, se cita a Leibniz y Hobbes, pero para su refutación. En lógica se advierte la inclinación hacia las tesis sensualistas (en las que destacaria más tarde un fulgentino, Ramón Campos, claramente influido por Condillac). Se condena el lujo inmoderado, aunque son partidarios del fomento del comercio, en especial si estimula la producción.

(67) A. MESTRE, «Religión y cultura...", pp. 717-743.

(68) Ibid.

(69) A. N. H. Cons., Leg. 5.496, Diligencia de visita... (1815).

(70) Ibid.

(71) J. A. LLORENTE, Historia critica de la Inquisición en España. Tomo IV, p. 105.

(72) A. GUY, "Ramón Campos, disciple de Condillac», en Pensee hispanique et philosophie française des lumieres. Universidad de Tolouse-Le Mirail, 1.980.

(73) A. H. N. Cons., Leg. 5.496, Diligencia de visita...

(74) Ibid.

(75) - Real provisión de 3 de septiembre de 1799, por la que se concede la gracia de que con seis matrículas, los colegiales teólogos pudiesen acceder a los grados mayores en cualquier universidad aprobada.

- Plan de estudios para derecho canónico, aprobado en la misma Real provisión.

- Plan de estudios para gramática latina, de 17 de agosto de 1801.

Todas estas disposiciones, así como el plan gubernativo de 23 de octubre de 1790 , se incluyen en las constituciones de 1803 (A. H. N., cons., Leg. 5.496).

$$
\text { D. Victoriano López... a su seminario conciliar..., } 1799 \text { (A. M. M.). }
$$


(77) Varias ediciones de esta obra en A. H. O.

(78) A. H. N. Cons., Leg. 5.496 Expte... sobre aprobación de las Constituciones, 1801.

(79) Ibid. Contestación de López Gonzalo, 10 de mayo de 1802.

(80) A. H. N. Cons., leg. 5.496, Diligencia de visita..., 1815.

(81) Proposiciones del mismo título. Murcia, Imprenta del ciudadano Mario Bellido, año 1821 (A. M. M.). 